\title{
Social Electricity: The evolution of a Large-Scale, Green ICT Social Application through two Case Studies in Cyprus and Singapore
}

\author{
Andreas Kamilaris*, Andreas Pitsillides \\ Department of Computer Science \\ University of Cyprus \\ Nicosia, Cyprus \\ Emails: kami@cs.ucy.ac.cy \\ andreas.pitsillides@ucy.ac.cy \\ * Corresponding author
}

\author{
Christos Fidas \\ Department of Cultural Heritage \\ Management and New Technologies \\ University of Patras \\ Patra, Greece \\ Email: fidas@ece.upatras.gr
}

\author{
Sekhar Kondepudi \\ Department of Building \\ School of Design and Environment \\ National University of Singapore \\ Singapore \\ Email: sekhar.kondepudi@nus.edu.sg
}

\begin{abstract}
Numerous green online social applications have emerged in recent years, aiming to motivate citizens towards proenvironmental behavior. These applications exploit emerging new technologies, such as mobile computing, online social networking and the web, in order to affect their users in their everyday lives. In this paper, we discuss our experiences from the threeyear development and management of Social Electricity, a largescale green online social application which targets influencing people to reduce their electricity footprint. We provide findings from two case studies performed in Cyprus and Singapore for six months, involving 198 and 175 participants respectively. Through these studies, we observed the acceptance, effectiveness and potential of Social Electricity, increasing our knowledge about the motivations that inspire people to take pro-environmental actions and the barriers that hinder them from acting in a sustainable way. Finally, we present the new version of Social Electricity, supporting citizens from all around Europe, carefully designed and developed based on the feedback received from these case studies and the accumulated expertise during these three years.
\end{abstract}

\section{INTRODUCTION}

Citizens around the world, especially in developed countries, tend to over-consume energy for their needs. This overconsumption has large implications on the physical environment and crosses the line of un-sustainability [1]. The residential sector is responsible for a significant fraction of global energy consumption, reaching $20-30 \%$ in some countries [2]. Hence, energy-saving initiatives and campaigns targeting the home setting are of particular importance.

Online applications targeting the environmental awareness of their users have proliferated in recent years, due to the appearance of emerging new information and communication technologies (ICT), such as high-speed Internet, broadband communications, the large adoption of smart phones, the popularity of online social networking and new capabilities in web development and mobile computing. These applications focus on motivating people to acquire more sustainable ways of life, by changing their everyday activities and habits.

Initially, online green applications counted solely on ecofeedback, which involved feedback comparing current behavior and actions (e.g. electricity footprint) with the past. Considering personal energy consumption in particular, studies showed that eco-feedback could influence residents to reduce it by a fraction of 5-15\% [3]-[5]. However, it was also observed that feedback alone was not enough, since people tend to lose their interest after some weeks or months [6]. Moreover, self-comparisons pose limitations due to their scope, since they consider only the individual's behavior and disregard his relative position among those of similar others [7].

To address these limitations, many ICT applications started including social aspects [8]-[12], taking advantage of the community effect, social influence and social pressure [13], as users tend to be influenced by their online contacts [9], [14]. Comparative feedback with others exploits the phenomenon of social norms, and in particular normative social influence, according to which people have a tendency to agree on values, beliefs, attitudes or behaviors of others [15], [16].

Social influence links to pro-environmental behavior because people generally engage in rewarding behaviors (e.g. satisfaction for preserving the environment, reduced bill on waste) and also tailor their actions towards avoiding adverse experiences such as feelings of guilt or shame [17]. Strong participation in sustainable actions is most likely when activities can be easily integrated into daily life [18], as is the case with online social networking today [19].

Although there are indications that such online applications exploiting the community effect (in terms of user influence and engagement), are more effective than eco-feedback alone, they still have some limitations reducing their overall effectiveness. These limitations span privacy and reliability issues, matters of (small) scale and offering of limited features that do not take into account recent technological advancements such as renewables.

In this paper, we describe the evolution of Social Electricity [20], [21], a large-scale online social application aiming to motivate users to reduce their electricity consumption. We explain the effectiveness, potential and limitations of the application, as derived from two case studies performed in Cyprus and Singapore for six months, involving 198 and 175 participants respectively. These two places were selected as they constitute the countries where the authors live, while in both countries 
the authors have good collaborations with the governmental local utilities. Based on the feedback from the participants, we tried to satisfy the needs and requirements of citizens in terms of personal energy management, re-designing Social Electricity in order to become a handy assistant in their efforts to reduce their electricity footprint. In general, including users in the design process of persuasive systems is highly desirable [22]. Moreover, this paper presents our efforts to address the limitations of related work, towards a complete online social platform targeting energy savings.

The rest of the paper is organized as follows: Section II reviews related efforts in the domain of green ICT applications. Then, Section III provides the initial design of the Social Electricity application three years ago. After, Sections IV and $\mathrm{V}$ describe the case studies performed in Cyprus and Singapore on the use of Social Electricity. Finally, Section VI presents the recent re-design of Social Electricity to address the limitations identified in the two case studies, and Section VII concludes the paper outlining future work.

\section{RELATED WORK}

Various online applications have leveraged online social networking and user collaboration to achieve energy reductions and promote sustainable actions. For example, HomeWeb [23], [24] is an application framework for web-based smart homes, promoting user collaboration through Facebook towards home automation and energy savings. CiteGreen [8] is a Web application inspiring people to perform actions for protecting the environment, giving credits to them for every sustainable action they commit. Various actions are supported such as recycling, transportation and energy savings.

StepGreen leverages social networking sites to promote energy-saving behaviors of users [9], [18]. This application encourages users to create/commit to green actions, share these actions with their friends and see their impact over time. In a three-week field study involving 32 people, it was observed that participants engaged in about 16 different actions, and reported completing about 100 actions per week.

Other applications leverage normative social influence and comparative feedback to affect citizens. EnergyWiz [10] is a mobile application that enables users to compare their consumption with their neighbors, contacts from social networking sites and other EnergyWiz users. A small evaluation using personal, semi-structured interviews and 17 individuals showed that social comparison features did not provide many learning benefits, mainly because the comparisons were performed with "not similar" people.

Wattsup [11] is an online application that displays live data from a commercial energy monitor, allowing users to compare domestic consumption with Facebook friends. After a competition for energy savings in eight homes over a 18day period, a significant reduction of energy was observed in comparison to a feedback-only approach, while the engagement with the application was five times more. A similar study in two blocks of six and 20 flats [25], for a period of one month at each, showed savings of $11.90 \%$ and $27.74 \%$ respectively, demonstrating the potential of competition as a feedback strategy.
A parallel and complementary service to our application is provided by the company OPOWER [26]. OPOWER started by sending energy report letters to customers, comparing their electricity use to that of their neighbors. This practice has contributed in reducing the overall domestic consumption by an average of $2 \%$ [27]. OPOWER has a social online application allowing users to compare their consumption with houses sharing similar characteristics (e.g. square meters, no. of tenants) [14]. Users can use the "Utility Connect" feature, to have their energy use automatically updated every month.

Recently, Welectricity [12] appeared as an online application that helps people to track and reduce their energy consumption at home by setting goals for reductions and by comparing their savings with their friends. Although it claims it has users from 112 countries, it offers only basic features. Generaytor [28] is a crowdsourcing platform that enables collaborative analysis by collecting and integrating performance data from users owning photovoltaics and solar panels. It provides users with simple insights into their electricity production, and ultimately ways to optimize their solar return on investment. Finally, Gridmates [29] uses innovative smart grid technologies to offer a unique ecosystem to eliminate energy poverty, by connecting utilities, non profit organizations, corporations and utility customers. Utility customers may help other people or organizations in need by sending electricity to their accounts.

The aforementioned applications, although they seem to be more effective and engaging than eco-feedback only platforms, they present some important limitations which hinder their larger popularity and adoption by the public. At first, most of them do not respect user privacy (OPOWER, EnergyWiz, Welectricity), as the consumptions or actions of the users are visible to others. Hence, many people are reluctant to participate. Some have been deployed only in a small scale for limited time (EnergyWiz, Wattsup). Some rely on the user to provide credible information (StepGreen, Welectricity) and this lowers the reliability of comparisons, since people could cheat by entering any value [30].

Furthermore, comparisons in some cases are not meaningful (EnergyWiz, Wattsup), since it is difficult for people to find "suitable others". Very few support new technologies such as renewables (Generaytor, Gridmates) while the education of the users about the relevant sustainable target(s) of the applications is not based on any modern, well-proven learning techniques. Finally, most of the applications follow the "one size fits all" approach, providing the same feedback to different individuals with various motivations for energy saving [31].

The main contribution of this paper is the presentation of the evolution of Social Electricity, an application that tries to reduce or avoid the limitations of related work, involving the users in the design process. We provide interesting insights about user perceptions, needs and requirements in using large-scale green ICT social applications, investigating several dimensions through the deployment of two large case studies in Cyprus and Singapore. Our contribution includes also a description of the design aspects of Social Electricity, as considered based on the experience gained during the two case studies, in an effort to develop an engaging and more complete platform that meets the needs of its users, for raising their energy awareness taking into account privacy concerns. 


\section{Social Electricity: The Beginning}

Social Electricity started in 2012 as an online social application allowing people to perform comparisons of their electrical consumption with their online friends and neighbors. Users can register either directly through the website or through Facebook. Facebook was selected because it is easy to access, widely used and well accepted by our target users. The application followed (some of) the design guidelines in [22], [32], [33] and was based on the promise that by providing effective features aiming to perform realistic comparisons, the consumers may perceive their electricity footprint and take steps to reduce their electricity and carbon footprint. The application exploits the "reveal and compare" pattern, which is one of the most influential patterns for persuasion in online social networks [34].

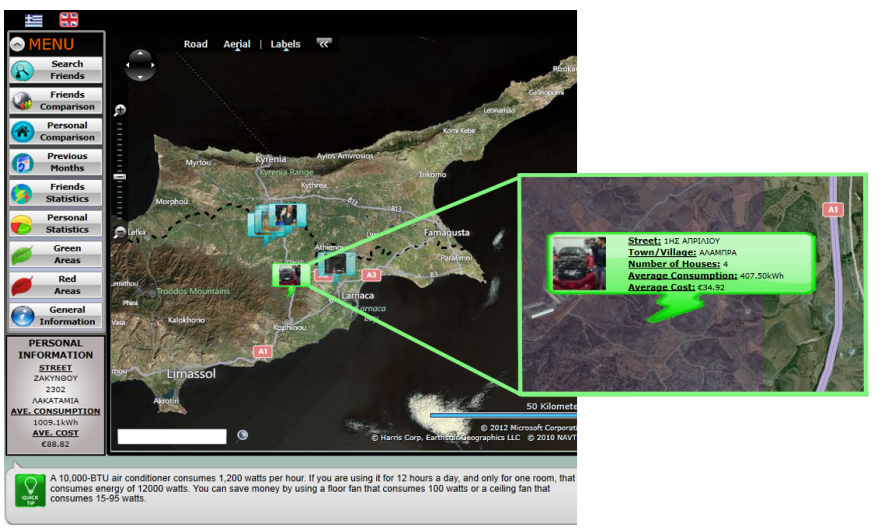

Fig. 1. A visualization showing the comparisons among Facebook friends.

The main scope of the initial version of the application was to provide comparative feedback to the users, allowing people to compare their energy footprint with Facebook friends (see Figure 1) or with the consumption at their neighborhood, village or town (see Figure 2, left), to perceive if their own consumption is low, average or high. The friends of a user are tagged on a geographic map, in their current place of stay. Friends with higher consumption are displayed in red color while friends with better energy behavior in green.

Moreover, a ranking between friends according to their consumption is given, starting from the greenest to the most red friend. Rankings are also offered about the most energyefficient streets and villages near the user's location, motivating people to acquire "region awareness", inspired to take actions to help the local community maintain a better ranking. Temporal comparative feedback is supported too, in regard to previous months and for the same month in previous years. Users may perform this comparison by including their friends' temporal patterns, as shown in Figure 2 (right).

Besides the main features, useful tips to people about saving energy are provided (see bottom bars in snapshots of Figures 1 and 2). Other features include statistics about the areas, villages and towns with the least/most energy consumption around the country and the option to associate electricity with actual costs, enabling users to have a more meaningful view of their energy profile. Finally, a competition is running every year, through which users can compete for savings with other people from their country, hence users have the motivation to

\begin{tabular}{|c|c|c|c|c|c|c|}
\hline & Male & Female & $\mathbf{1 8 - 2 4}$ & $\mathbf{2 5 - 3 4}$ & $\mathbf{3 5 - 4 9}$ & $\mathbf{5 0 - 6 4}$ \\
\hline $\mathbf{N}$ & 126 & 72 & 62 & 97 & 32 & 7 \\
\hline $\mathbf{\%}$ & 63.6 & 36.4 & 31.3 & 49.0 & 16.2 & 3.5 \\
\hline
\end{tabular}

TABLE I. DEMOGRAPHICS OF THE PARTICIPANTS AT THE CASE STUDY IN CYPRUS.

improve their ranking and achieve savings. The most energyefficient users at the end of each competition are recognized by the application through badges and tokens of appreciation.

\section{CAse Study 1: Citizens of Cyprus}

Social Electricity was first deployed in Cyprus, by collaborating with the Electricity Authority of Cyprus (EAC) [35], which is the governmental electric utility. EAC provided anonymous access to the country's domestic consumption, categorized according to the streets of the consumers for the last three years. This data includes the measurements of around 300,000 domestic premises, collected every two months. From this data, users can select the average consumption of their street as their personal one, or they can add their own consumption each month. Several months after its release, Social Electricity counted more than 1,500 users living in Cyprus, who voluntarily registered to the application.

A user study aiming to investigate user perceptions relating to Social Electricity was conducted six months after the release of the application to the public [36], [37]. This study aimed to address the following research questions:

1) How effective and useful is the concept of Social Electricity for raising energy awareness?

2) What are the motivations influencing people to reduce their consumption?

3) Which are the privacy concerns and the limits for sharing electricity consumption data in a large-scale online social application?

4) What is the potential of green ICT applications that employ normative social influence?

The study involved an online survey, conducted to collect empirical evidence on the importance of quality factors relating to the use of the application. An online questionnaire was formed consisting of 65 questions. The research questions were grouped in five categories: a) demographics (sex, age, education, income); b) usefulness and influence; c) motivations; d) privacy; and e) potential. A five-point Likert scale was used to rank the level of importance from "Not Important (1)" up to "Most Important (5)".

Participants' recruitment was performed by sending invitations through email to the users of the application. A total of 198 people accepted the invitation to participate in the survey, out of the 1,5000 (current) users of the application (13.2\%). The distribution in age groups is depicted in Table I. Males were the majority of the sample $(63.6 \%)$. The most popular age group was 25-34 years old $(\mathrm{N}=97$, freq=49\%).

After the survey, two semi-structured mini focus group sessions [38] were conducted based on the subjective preferences and perceptions of the questionnaire's respondents on the provided features, and their influence towards energy awareness. The specific themes under discussion were selected after the analysis of the questionnaire, focusing on themes in which the questionnaire analysis did not provide clear insights. 

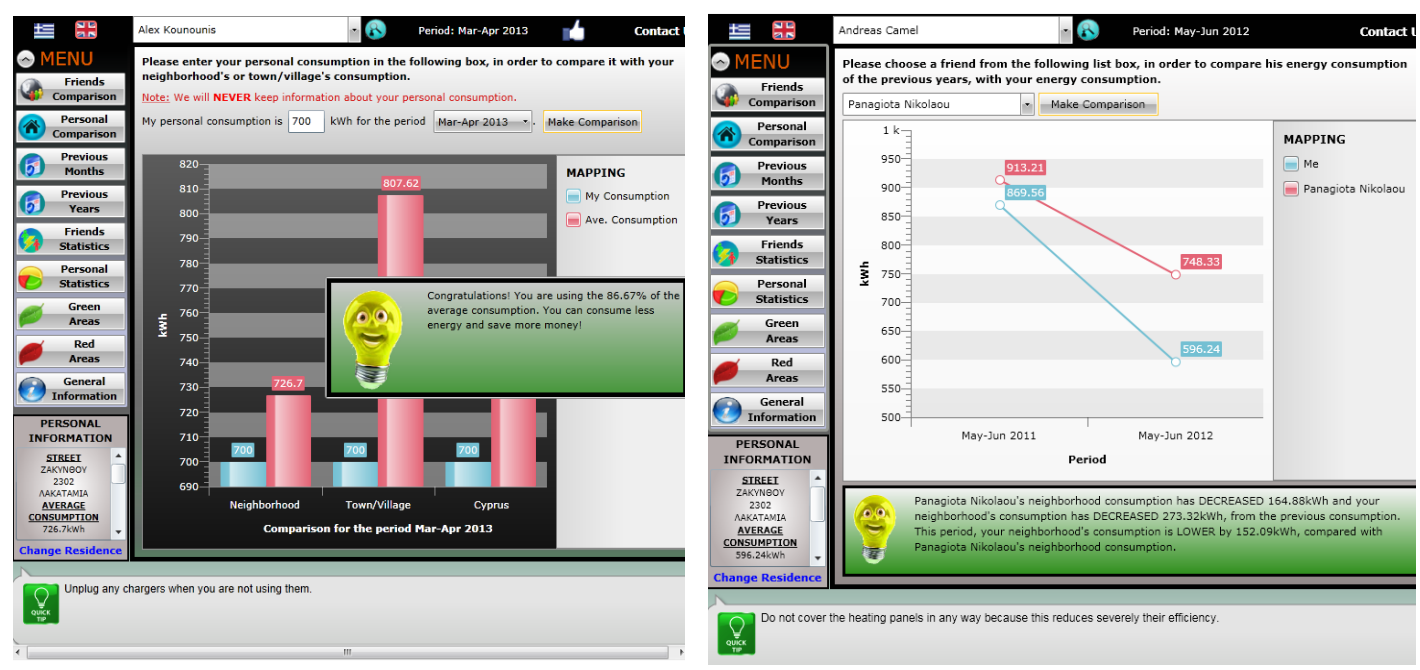

Fig. 2. Normative comparative feedback in neighborhood level (left). Temporal comparative feedback, comparing also with a friend's street. (right).

Participants at the focus groups were recruited by sending email invitations to the users of the application. The focus groups were divided in two categories, selected in a way to best represent Cypriot users, as the large majority of our users (75\%) fitted into these two categories. Each category included seven people (4 male - 3 female): a) students (18-24 years old) living with their parents not paying any electricity bills; and b) citizens who live and work in Cyprus (26-32 years old).

\section{A. Findings from the Case Study in Cyprus}

Both the participants at the questionnaires and at the focus groups had a general consensus about the (positive) value of the application. The participants stated clearly the requirement of sharing personal energy consumption data through a privacy policy that satisfies the ability of revealing energy consumption on a street and home level to different user categories inside social networking applications. In summary, the main findings of this study were the following ${ }^{1}$ :

- Local and social comparative feedback techniques are useful in helping people to perceive the amount of energy they consume (low, medium or high).

- Users prefer easy to understand information regarding their consumption and simple ways to reduce it.

- Different user groups are engaged with different ecofeedback features. Younger people prefer energysaving tips while older people are interested in comparative feedback.

- Different user groups have different incentives and motivations. Financial incentives motivate older people while social norms are more effective in younger people. High-income citizens prefer environmental incentives that pecuniary motives.

- There is a need for more personalized feedback strategies, taking into account user profiling, home characteristics, incentives and motivations.

\footnotetext{
${ }^{1}$ Please refer to [36] for more details about this study.
}

- Social comparative feedback may not seem very effective as a feedback technique, however, when green ICT applications involve social characteristics, it is easier to grow their user communities and engage more people.

- When eco-feedback is delivered within a sociallyenabled context, the effect of losing interest after some time can be mitigated or even avoided.

- Comparative feedback with others needs to consider home characteristics and weather conditions, to make comparisons more realistic, meaningful and fair.

- Users are concerned about the sharing of their personal consumption data among their contacts and a privacy policy needs to be applied that satisfies the ability to control this sharing.

- Electric utilities have the social responsibility of offering various eco-feedback services to their consumers.

- Comparisons of electrical consumption between citizens of different countries and cultures is an interesting feature, in order to exchange know-how and experiences with different cultures.

\section{CAse Study 2: University Students in SINGAPORE}

Social Electricity was then deployed in Singapore, after acquiring the domestic consumption around the country by Singapore Power (SP) [39], which is the governmental electric utility, similar to the case of Cyprus. The case study took place during the spring semester of the National University of Singapore, involving 175 students from two different undergraduate courses offered by the Department of Building: PF1105 (Intelligent Buildings) and PF3303 (Facilities Management).

The use of Social Electricity was assigned to the students as a semester project. Table II lists the demographic characteristics of the students.

Most students lived with their parents (85\%), who also paid the electricity bills of the house (93\%). Students living in flats 


\begin{tabular}{|c|c|c|c|c|c|c|}
\hline & Male & Female & $\mathbf{1 8 - 2 4}$ & $\mathbf{2 5 - 3 4}$ & $\mathbf{3 5 - 4 9}$ & $\mathbf{5 0 - 6 4}$ \\
\hline $\mathbf{N}$ & 59 & 116 & 157 & 15 & 0 & 0 \\
\hline$\%$ & 33.7 & 66.3 & 89.7 & 10.3 & 0 & 0 \\
\hline
\end{tabular}

TABLE II. DEMOGRAPHICS OF THE PARTICIPANTS AT THE CASE STUDY IN SINGAPORE.

declared low-to-average family incomes, while those living in houses claimed average-to-high family incomes. Students were asked to add their personal consumption each month, as acquired by SP. We instructed them to send us their bill at the end of each month, to validate that they added correct information to the application. To facilitate historical comparisons, personal consumption data was collected on a monthly basis for a period of one year before the study started. This study aimed to address the following research questions:

1) Which motivational factors can influence students to become more aware about energy consumption?

2) Which incentives can be used for better motivating students about reducing their electricity footprint?

3) How can students perceive their electricity footprint and take actions to reduce it?

4) How can an online, social energy management platform affect students towards energy savings?

5) Which specific eco-feedback services and persuasive methods used in Social Electricity have the largest impact on students?

6) Which are the main difficulties hindering the students from achieving savings at home?

To motivate students to actively participate in the exercise, we graded their overall participation with a $5 \%$ bonus on their final grade. In order to get this bonus, they were instructed at the end of the semester to prepare a final report, explaining whether and how they used the application, whether and how it influenced their everyday habits and actions and to list the difficulties they experienced for saving energy, as well as ideas for generally influencing young people to become more aware about energy and the environment.

At this case study, Social Electricity supported the recording of the students' actions during the semester, i.e. when they logged in the application, which features they used and for how long. To avoid bias over some features in contrast to others, we designed the application in a such as that each user needed exactly two clicks to navigate to each feature from the home menu, as displayed in Figure 3. This version of the application supported also consumption of gas, since gas is used in the majority of households in Singapore. These possibilities were absent at the first case study in Cyprus.

\section{A. Findings from the Case Study in Singapore}

Regarding visits, most of the visits occurred at the beginning (mainly for curiosity) and at the end of the exercise (to perform the final report), as expected. In average, each student visited the application four times during the semester period. Through the final report, students explained that frequency of use was low mainly because the data was updated only once per month, primarily since the utility bills were provided by the electric utility once a month.

Concerning the popularity of eco-feedback services as used by the students, Table III lists the features used by the students during the semester. The fourth and fifth columns of the table

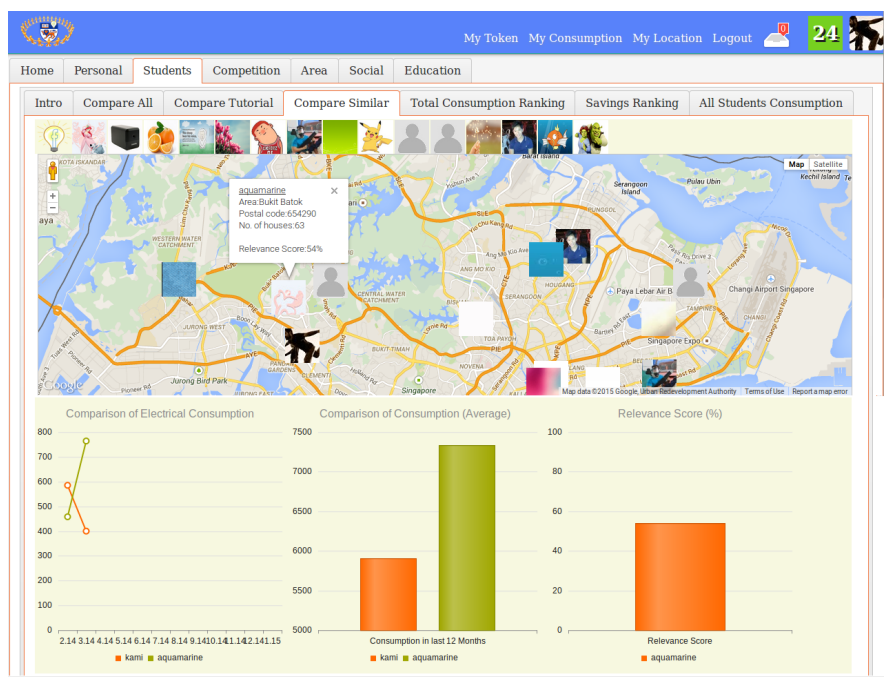

Fig. 3. A visualization showing the comparisons among Facebook friends.

show the total times each feature was used by the students during the semester and the average duration in seconds. Also, the various features are sorted in the table according to their popularity (number of visits).

Historical comparisons of personal consumption (Table III \#1, \#3) were very popular, as they helped the users to monitor their personal savings. Also, the competition (Table III \#2) was extensively used, helping the students to understand how their efforts for savings related to their colleagues. The duration of the use of the competition at each visit was the largest among all features, indicating the increased interest of the students to compete with each other for savings.

Comparing total consumption and savings among students each month (Table III \#4, \#5, \#6) was found interesting, as it helped the students to perceive their electricity footprint, whether they consumed low/average/high amounts of energy. The area-related and educational features (Table III \#7, \#9, \#10) were not regularly used by the students. A reason is that they do not constitute engaging services, providing mainly static information that does not change often.

In summary, the main findings of the user study in Singapore were the following:

- Students were not well educated on how to efficiently use domestic electrical equipment.

- Students mainly preferred detailed feedback on their personal consumption, including historical comparisons and breakdown per electrical appliance.

- Having some commitment (e.g. goal setting for savings) was important, encouraging students to try harder to achieve this goal.

- Students who perceived their footprint as high, accomplished larger percentages of savings. Low income of the family could be an additional motivation.

- Social ICT applications need to be more detailed and precise about the personal consumption of their users (e.g. offer breakdowns of consumption according to the particular electrical appliances used at each home). 


\begin{tabular}{|c|c|c|c|c|}
\hline No. & Feature Name & Description & Visits & Duration \\
\hline 1. & Compare with Previous Month & Personal comparison of electricity consumption with previous months. & 517 & $39.57 \mathrm{sec}$ \\
\hline 2. & Competition & Competition among students for the most savings during the exercise. & 391 & $72.34 \mathrm{sec}$ \\
\hline 3. & Compare with Previous Year & Personal comparison of consumption with same month in previous years. & 372 & $21.54 \mathrm{sec}$ \\
\hline 4. & Compare with Tutorial Students & Comparison of consumption with students from the same tutorial group. & 289 & $35.99 \mathrm{sec}$ \\
\hline 5. & Compare with All Students & Comparison of consumption with all students from the same course. & 275 & $42.46 \mathrm{sec}$ \\
\hline 6. & Students Consumption Ranking & Monthly ranking of total consumption among students. & 259 & $28.61 \mathrm{sec}$ \\
\hline 7. & Area Comparisons & Comparison of consumption with the street where the user lives. & 248 & $23.93 \mathrm{sec}$ \\
\hline 8. & Compare with Similar Students & Compare only with students sharing similar home characteristics. & 231 & $29.74 \mathrm{sec}$ \\
\hline 9. & Translation & Translation of consumption from kilowatt-hours into more meaningful values (money, $\mathrm{CO} 2$ etc.). & 194 & $50.44 \mathrm{sec}$ \\
\hline 10. & Tips for Savings & Tips for energy savings at home. & 170 & $42.32 \mathrm{sec}$ \\
\hline
\end{tabular}

TABLE III. LIST OF FEATURES PROVIDED B Y SOCIAL ELECTRICITY AND THEIR USE DURING THE CASE STUDY IN SINGAPORE.

- Social ICT applications need to be more personalized, offering specific advice for savings according to each user's preferences and home characteristics, and not only general information and comparisons.

- Information needs to be frequent (e.g. near real-time or every few minutes) and -if possible- to include details of the consumption of particular key electrical appliances (e.g. air conditioner, television, water heater).

- Comparisons need to be fair, taking into account the physical and weather characteristics of each house/area respectively.

The final reports revealed the main difficulties hindering the students from achieving savings. These difficulties are:

- Many people in the house. "It is challenging as there are five of us at home and each of us has his own needs to use electricity". "Actions on my part may have been offset by extra energy consumed by other family members".

- Level of comfort. "For example, it is rather difficult to suddenly alter the amount of water used for bathing or to take an alternative measure of using the fan instead of the air conditioner".

- Change requires time. "Given a longer period, we will change our routine behavior gradually and there will be a reduction in our utility bills some months later".

- Lack of incentives. "I did not have much motivation to do that extra step to reduce the amount of energy that I consume at home".

- Limitations of eco-feedback. "Feedback should be more frequent".

- Level of detail. "The application needs to support a breakdown representation of the overall consumption according to the electrical appliances of the house".

Finally, we asked the students to write in the final reports about how to address the problem of motivating young people, who do not have (direct) financial incentives, to become more aware about energy. A summary of their responses is provided:

- Role of parents. Parents can share their savings with their children, give them rewards/gifts for savings or recognition to those who actively participate in energy saving activities.

- Role of school. Integrating energy-saving initiatives to the grading system, competitions for energy savings, specialized courses/events educating about the pros of saving energy and the consequences of wastage.
- Role of utilities. Rewards/discounts on the bills of customers who achieve savings, estimation of the appropriate amount of energy that should be consumed per house, offering of more fair bills, including personal advice and incentives for savings.

- Monetary incentives. Coupons for discounts, small gifts such as energy saving light bulbs or mascots used as reminders for greener behavior, vouchers and tokens of appreciation.

- Competitions, events and games. Points earned through the games could be converted into credits to redeem gifts.

- Environmental incentives. Measuring the precise impact of our actions on the environment, emphasis on the adverse consequences if we do not protect the environment.

- Commitment. Assigning attainable/reachable goals for energy savings, acknowledging students as "energy ambassadors" of their family, being responsible for the consumption at their house.

\section{DISCUSSION}

At first, we need to note that our samples are skewed towards age groups that are not responsible for paying bills, especially the case of the students in Singapore. It would have been more appropriate to conduct the studies among household members with some authority and responsibility for bill payments within the household. It is still interesting however to observe how young people, without direct financial incentives, face the challenge of energy conservation, by using an online, social energy management tool as an assistant.

From the two case studies, it seems that people are asking for more personalized and targeted feedback about their consumption. They seek for the right tools to manage their overall footprint in a simple and interactive way. They wish to share their consumption, goals and savings with their friends and the online community but they ask for being able to control this sharing, demanding from online green ICT social applications to respect their privacy. Moreover, users require from such applications to support a variety of eco-features and new technologies such as renewables, as well as interactive learning tools, relevant educational material and social games.

The ideal application must offer increased interactivity, supporting and promoting communication and collaborative activities, inside a highly dynamic and evolving context. A shift is required from online social applications to collective awareness platforms (CAPs) [40], defined as a special category 
of social networking applications aiming to motivate collective human action in favor of social welfare. Such platforms could assist in raising the energy awareness of citizens by increasing their sense of group membership, leading to higher correlations between social norms and behavioral intentions.

Addressing all the barriers hindering people to act proenvironmentally is not easy, and requires new design considerations and involvement of multiple stakeholders and relevant actors. During the last year, we tried to understand the needs and requirements of citizens in terms of managing their energy consumption and becoming educated about good energysaving practices, and we re-designed Social Electricity aiming to reduce the limitations people were facing with existing green ICT social applications. Some snapshots of the new version of Social Electricity are illustrated in Figure 4.

Table IV lists the limitations identified in related work (see Section II) and derived by the users at the two case studies in Cyprus and Singapore (see Sections IV and V), and presents the new features added to Social Electricity to reduce or overcome these limitations. The last column of the table lists the importance of each limitation/feature, as perceived by the participants of the case studies and by the authors.

An important goal during the re-design of Social Electricity was the inclusion of well-accepted individual determinants of energy use, such as attitude and knowledge, personal experience, locus of control, self-efficacy, responsibility, commitment, perceived norms and environmental attitudes and beliefs [43]-[45]. Aiming to link these determinants with the design of intervention techniques to encourage pro-environmental behavior [46], we included features such as goal setting (responsibility, commitment - Table IV \#5), educational content (attitude and knowledge, self-efficacy, environmental beliefs - Table IV \#9, \#10, \#11, \#12), targeted and personalized advice (self-efficacy, environmental beliefs - Table IV \#9), user interaction and collaboration (responsibility, commitment, perceived descriptive norms - Table IV \#8) and fair comparisons with other users (perceived descriptive norms - Table IV \#7). We also tried to demonstrate through the various features that the actions of the occupants would have a considerable impact (locus of control - Table IV \#5, \#7, \#9, \#10, \#14).

The two case studies indicated that users have different motivations and incentives, according to their profiles and demographics. For example, financial incentives motivate mostly older people while environmental sensitivity affects highincome citizens more than financial motives. Thus, according to the profile of each user, more personalized feedback is provided in some features (Table IV \#9, \#10), which is in line with the most effective motivations of each user group as identified through the case studies performed in Cyprus and Singapore.

Multiple feedback types are better for generating positive response, activating different motives, beliefs and norms [13], [46]. Instructional interventions (education, advice) are effective to change one's attitude and intentions while motivational and supportive interventions (goals, comparisons, communication) can be more effective to influence people when their anti-environmental behaviors have become a habit. Thus, Social Electricity supports multiple feedback types blending instructional and supporting interventions.
Apparently, there are some limitations which have only partly been addressed. For example, support for real-time data requires from the users to install smart energy monitors connected to the Internet (unless the utility provides support for smart metering in houses, and it is willing to share this information with Social Electricity). Moreover, collaboration with energy utilities and agencies for more accurate consumption information of users and the possibility of obtaining their consumption information directly from their utility (after the users have authenticated as owners of their claimed premise) is an open issue, even though Social Electricity provides the technical infrastructure to support this capability. It is important to mitigate or avoid the phenomenon of people cheating by entering any value to the application [30]. Collaboration with utilities could be extended to provide financial incentives for energy savings e.g. reductions on the bills of customers who achieve substantial savings.

Some limitations not mentioned, which could be essential features in future green ICT social applications, involve the creation of user groups (e.g. friends, colleagues, relatives) for a collaborative and coordinated effort for energy savings while some form of incentives for people to help others to save energy using their expertise/experience (e.g. through a pointing system that gives points to users when they provide effective solutions to other peers) would be interesting. New technologies such as smart grid programs (e.g. demand response, load shedding) [29], [47], [48] could create new limitations, hence the evolvement of Social Electricity needs to be continuous.

Some general limitations discussed in related work [22], [32], which hold for Social Electricity too, are the following:

- Eco-feedback technology should be attempting to impact both efficiency consumption behaviors and curtailment behaviors [49].

- When a pro-environmental behavior is achieved, how does eco-feedback avoid losing its importance?

- How does an online green ICT application model and perceive the stages of behavior change of its users (e.g. based on the Transtheoretical Model [50]), and how does it provide personalized feedback accordingly?

- Move beyond the individual, by also considering community, political, and infrastructural engagement.

- Shift from prescription to reflection, encouraging users to reflect on what it actually means to be sustainable in a way that makes sense in the context of their lives.

- $\quad$ Shift from behaviors to practices, i.e. rather than focusing on specific, isolated behaviors, consider energy in the context of broader sociocultural practices.

\section{CONCLUSION}

In this paper, we presented the main findings and experiences from two large case studies performed in Cyprus and Singapore for six months, involving 198 and 175 participants respectively. Through these findings, the evolution of a large-scale green ICT application called Social Electricity was described, which targets energy savings of its users in a collaborative manner. Social Electricity tries to address the limitations and barriers that hinder people from taking 

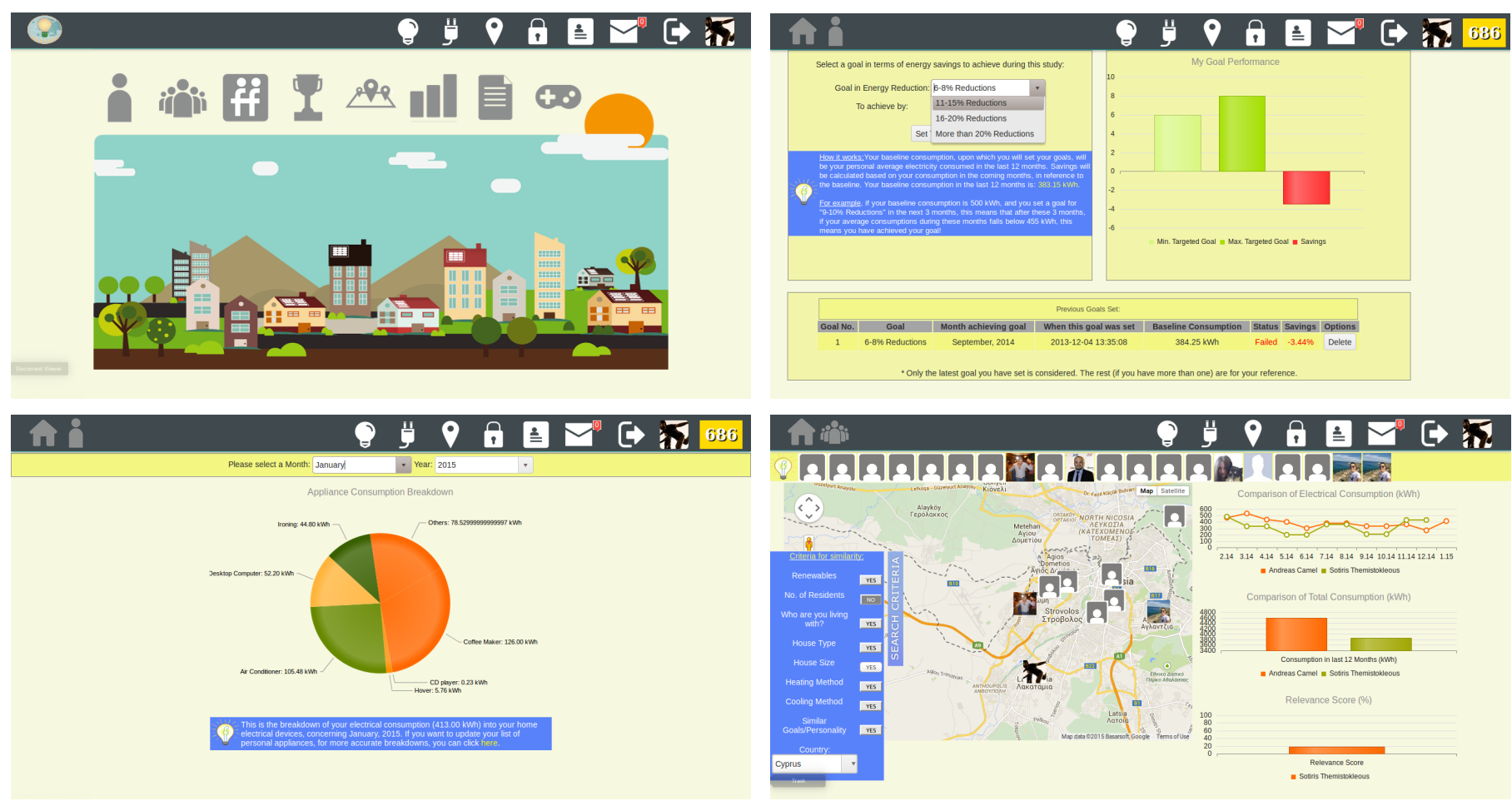

Fig. 4. Social Electricity main menu (top-left). Setting goals for energy savings. (top-right). Detailed breakdown of overall consumption per electrical appliance (bottom-left). Comparison of production/consumption with similar users (bottom-right)

pro-environmental actions and aims to meet the needs and requirements of citizens in respect to the demand of an online social tool for personal energy management. We listed these limitations, as identified in related work and we explain how we addressed them through Social Electricity, involving the users in the design process of the application [22].

For future work, we plan to offer better solutions for some limitations which have not been addressed or have been addressed only partly (e.g. real-time feedback, accuracy of consumption measurements), and provide effective support for emerging new technologies, such as renewable energy sources, domestic smart grid applications (e.g. demand response, load shedding) [29], [47], [48] and micro-grid scenarios such as local, collaborative production and consumption of electricity. Also, we aim to address the more general limitations discussed in related work [22], [32], listed in the previous section.

Finally, through the Social Electricity Online Platform (SEOP) European project [42], funded by the Lifelong Learning Programme, we plan to perform further research among more relevant samples over a longer timeframe, including participants from various European countries including Cyprus, Greece, Malta, Austria, Slovenia, Slovakia, Lithuania and Ireland. In parallel, in collaboration with the National University of Singapore, we are starting a pilot involving the installation of 50 smart meters in various domestic premises around Singapore, aiming to examine how real-time electricity consumption information affects the overall engagement/behavior of the users, through an online social energy management tool such as Social Electricity.

\section{ACKNOWLEDGMENT}

We would like to thank the Electricity Authority of Cyprus, the Singapore Power and GeoPostcodes for their valuable help and support. We thank also the citizens of Cyprus who are users of Social Electricity, especially those who participated in our online questionnaires and the focus groups. Special thanks as well to the students of the National University of Singapore who participated in our semester exercise. This study has been performed during the Social Electricity Online Platform (SEOP) project, and it has been co-funded by the European Commission (3375-LLP-1-2013-1-CY-KA3-KA3MP). This publication reflects the views only of the authors, and the Commission cannot be held responsible for any use which may be made of the information contained therein.

\section{REFERENCES}

[1] Annie Leonard. The story of stuff: How our obsession with stuff is trashing the planet, our communities, and our health-and a vision for change. Simon and Schuster, 2010.

[2] Kurtis McKenney, Matthew Guernsey, Ratcharit Ponoum, and Jeff Rosenfeld. Commercial Miscellaneous Electric Loads: Energy Consumption Characterization and Savings Potential in 2008 by Building Type, 2010. Technical Report D498: 224.

[3] Sarah Darby. The effectiveness of feedback on energy consumption A review for defra of the literature on metering, billing and direct displays. Environmental Change Institute, University of Oxford, 2006.

[4] Kat A. Donnelly Karen Ehrhardt-Martinez and John A. Laitner. Advanced Metering Initiatives and Residential Feedback Programs: A Meta-Review for Household Electricity-Saving Opportunities, Research Report E105. American Council for an Energy-Efficient Economy, 2010. http://aceee.org/research-report/e105.

[5] G. Wood and M. Newborough. Dynamic energy-consumption indicators for domestic appliances: environment, behaviour and design. Energy and Buildings, 35(8):821-841, 2003. 


\begin{tabular}{|c|c|c|c|}
\hline No. & Limitation & New Feature & Importance \\
\hline 1. & $\begin{array}{l}\text { Scale of the application: Not possible to interact and com- } \\
\text { pare a user's consumption with people from different coun- } \\
\text { tries/cultures. }\end{array}$ & $\begin{array}{l}\text { Pan-European support: Users can interact and compare their } \\
\text { footprints with citizens of other countries/cultures in Europe. }\end{array}$ & High \\
\hline 2. & $\begin{array}{l}\text { Violation of privacy: Not able to control the sharing of con- } \\
\text { sumption data with other users. }\end{array}$ & $\begin{array}{l}\text { Privacy menu: Users can specify the sharing of their location, } \\
\text { consumption information, and whether to allow interaction with } \\
\text { other groups of users. Interaction is also possible by using a } \\
\text { username instead of a real name. }\end{array}$ & High \\
\hline 3. & Real-time feedback & $\begin{array}{l}\text { Offering support for real-time data from smart energy monitors } \\
\text { (currently supporting CurrentCost monitors [41]). Users can } \\
\text { view their consumption in near real-time and perform real-time } \\
\text { comparisons with other users. }\end{array}$ & High \\
\hline 4. & Accuracy of consumption measurements & $\begin{array}{l}\text { Collaborated with EAC in Cyprus for validating consumption } \\
\text { information provided by the users and for providing more ac- } \\
\text { curate aggregated data and statistics. Looking for collaboration } \\
\text { with other energy utilities from other countries as well. }\end{array}$ & High \\
\hline 5. & $\begin{array}{l}\text { Goal setting: Users want to be able to set goals about future } \\
\text { savings. }\end{array}$ & $\begin{array}{l}\text { Goal setting menu: Users can set goals for future savings and } \\
\text { monitor their performance through time (see Figure } 4 \text {, top- } \\
\text { right). }\end{array}$ & High \\
\hline 6. & $\begin{array}{l}\text { Breakdown of consumption: Users want to have a detailed } \\
\text { breakdown of their consumption per electrical appliance used } \\
\text { at their home. }\end{array}$ & $\begin{array}{l}\text { Users are able to add a list of the electrical appliances they } \\
\text { use at their home, recording the season, frequency per month, } \\
\text { duration of use each time and consumption. Then, by selecting } \\
\text { some particular month, they can view a detailed breakdown } \\
\text { of their consumption per device and the contribution of each } \\
\text { appliance to the total consumption (see Figure } 4 \text {, bottom-left). }\end{array}$ & High \\
\hline 7. & $\begin{array}{l}\text { Fair comparisons: Users want to compare their consumption } \\
\text { only with citizens having similar profiles and house character- } \\
\text { istics. }\end{array}$ & $\begin{array}{l}\text { Users can add the characteristics of their house (type and size, } \\
\text { heating/cooling method, number of residents etc.) and locate } \\
\text { other users with similar preferences, based on a similarity rank. } \\
\text { They can search for similar others from all around Europe (see } \\
\text { Figure 4, bottom-right). }\end{array}$ & High \\
\hline 8. & $\begin{array}{l}\text { User interaction and collaboration: Users need to interact with } \\
\text { other users to exchange knowledge, experience and expertise } \\
\text { about good practices in saving energy and the use of renewable } \\
\text { technologies. }\end{array}$ & $\begin{array}{l}\text { Users can directly communicate with other citizens (if they } \\
\text { allow it), through email, online social networking or use the } \\
\text { direct messaging feature of Social Electricity. }\end{array}$ & High \\
\hline 9. & $\begin{array}{l}\text { Personalized feedback: Users want more targeted advice on } \\
\text { which actions would help them save energy. }\end{array}$ & $\begin{array}{l}\text { By analyzing the electrical appliances used by each user, } \\
\text { together with the details of how they make use of them and } \\
\text { which is their consumption, Social Electricity provides specific, } \\
\text { targeted advice on how to use these appliances in an energy- } \\
\text { efficient manner. }\end{array}$ & High \\
\hline 10. & Education based on modern techniques & $\begin{array}{l}\text { Providing highly interactive, online learning modules with latest } \\
\text { advances on households' energy saving methods and tech- } \\
\text { niques, options and potential of various renewable technologies, } \\
\text { tips for savings and online videos. Users can complete the } \\
\text { modules and answer some relevant questions at the end of each } \\
\text { one, receiving a score indicating their knowledge [42]. }\end{array}$ & High \\
\hline 11. & $\begin{array}{l}\text { Interactive social games: Learning about energy/electricity } \\
\text { through games. }\end{array}$ & $\begin{array}{l}\text { Offering four different online games aiming to increase the } \\
\text { knowledge of users on various aspects of energy. These games } \\
\text { are: pairs quiz, time quiz, crossword and letter soup. Users can } \\
\text { compare their scores at the games with the online community } \\
\text { and their friends. }\end{array}$ & Medium \\
\hline 12. & $\begin{array}{l}\text { New technologies: Supporting new technologies for households } \\
\text { such as renewables. }\end{array}$ & $\begin{array}{l}\text { New technologies are supported in two different ways: a) } \\
\text { users can specify the renewable technology they use at their } \\
\text { home, and then locate similar others in Europe to share their } \\
\text { experiences and compare their production/consumption; and b) } \\
\text { the online learning modules can educate the users on latest } \\
\text { advancements in green technologies. }\end{array}$ & High \\
\hline 13. & $\begin{array}{l}\text { Statistics: Be able to observe statistics about the energy con- } \\
\text { sumption of different areas. }\end{array}$ & $\begin{array}{l}\text { Users can view statistics about the monthly consumption of } \\
\text { all towns, cities, countries of Europe, as these values are } \\
\text { provided by the online user community of Social Electricity. } \\
\text { They can examine which are the most/least energy-efficient } \\
\text { towns/cities/countries of Europe each month. }\end{array}$ & Low \\
\hline 14. & $\begin{array}{l}\text { Area performance: Users want to compare how their area } \\
\text { performs in comparison to other areas of their country. }\end{array}$ & $\begin{array}{l}\text { Users can view detailed graphs about the monthly ranking of } \\
\text { their area/town/city/country in respect to their country or in } \\
\text { relation to the rest of Europe. They can observe the most/least } \\
\text { energy-efficient areas/cities of their country each month. }\end{array}$ & Low \\
\hline
\end{tabular}

TABLE IV. LIMITATIONS OF ONLINE GREEN ICT SOCIAL APPLICATIONS AND NEW FEATURES AT SOCIAL ELECTRICITY.

[6] Sarah Darby. Making it Obvious: Designing Feedback into Energy Consumption, pages 685-696. Springer Berlin Heidelberg, 2001.

[7] C. Egan. Graphical Display and Comparative Energy Information: What Do People Understand and Prefer? In Proceedings of the Summer Study of the European Council for an Energy Efficient Economy, 1999.

[8] CiteGreen, 2015. https://www.citegreen.com/.

[9] Jennifer Mankoff, Susan R. Fussell, Rachel Glaves, Catherine Grevet, Michael Johnson, Deanna Matthews, H. Scott Matthews, Robert 
McGuire, Robert Thompson, Aubrey Shick, and Leslie Setlock. StepGreen.org: Increasing energy saving behaviors via social networks. In Proc. of the International AAAI Conference on Weblogs and Social Media (ICWSM), Washington, DC, USA, 2010. AAAI Press.

[10] Petromil Petkov, Felix Köbler, Marcus Foth, and Helmut Krcmar. Motivating domestic energy conservation through comparative, communitybased feedback in mobile and social media. In Proceedings of the 5th International Conference on Communities and Technologies, pages 21-30, New York, NY, USA, 2011. ACM.

[11] Derek Foster, Shaun Lawson, Mark Blythe, and Paul Cairns. Wattsup? motivating reductions in domestic energy consumption using social networks. In Proceedings of the 6th Nordic Conference on HumanComputer Interaction: Extending Boundaries, NordiCHI '10, pages 178-187, New York, NY, USA, 2010. ACM.

[12] Welectricity Inc. Welectricity, 2015. http://www.welectricity.com/home.

[13] Corinna Fischer. Feedback on household electricity consumption: a tool for saving energy? Energy Efficiency, 1(1):79-104, 2008.

[14] OPOWER. Social Application, 2015. https://social.opower.com/.

[15] Robert B. Cialdini. Influence: science and practice. Allyn and Bacon, 2001.

[16] Deutsch, M., and Gerard, H.G. A study of normative and informational social influence upon individual judgment. Journal of Abnormal and Social Psychology, 51:629-636, 1955.

[17] B.J. Fogg. Persuasive Technology: Using computers to change what we think and do. Morgan Kaufmannn, 2003.

[18] Jennifer Mankoff, Deanna Matthews, Susan R. Fussell, and Michael Johnson. Leveraging social networks to motivate individuals to reduce their ecological footprints. In Proceedings of the 40th Annual Hawaii International Conference on System Sciences, HICSS '07, pages 87-, Washington, DC, USA, 2007. IEEE Computer Society.

[19] Nielsen Online Report. Global Faces and Networked Places, 2009. http://blog.nielsen.com/nielsenwire/global/social-networkingnew-global-footprint/.

[20] Andreas Kamilaris, George Taliadoros, Diomidis Papadiomidous, and Andreas Pitsillides. The practice of online social networking of the physical world. International Journal of Space-Based and Situated Computing (IJSSC), 2(4):240-252, 2012.

[21] Andreas Kamilaris, Diomidis Papadiomidous, and Andreas Pitsillides. Lessons Learned from Online Social Networking of Physical Things. In Sixth International Conference on Broadband and Wireless Computing, Communication and Applications (BWCCA), Barcelona, Spain, October 2011.

[22] Hronn Brynjarsdottir, Maria Håkansson, James Pierce, Eric Baumer, Carl DiSalvo, and Phoebe Sengers. Sustainably unpersuaded: How persuasion narrows our vision of sustainability. In Proceedings of the SIGCHI Conference on Human Factors in Computing Systems (CHI), pages 947-956, Austin, Texas, USA, 2012. ACM.

[23] Andreas Kamilaris and Andreas Pitsillides. Social networking of the smart home. In 21st Annual IEEE International Symposium on Personal,Indoor and Mobile Radio Communications (PIMRC 2010), Istanbul, Turkey, September 2010.

[24] Andreas Kamilaris, Andreas Pitsillides, and Michalis Yiallouros. Building energy-aware smart homes using web technologies. Journal of Ambient Intelligence and Smart Environments (JAISE), 5(2):161-186, 2013.

[25] Andreas Kamilaris, Giannis Kitromilides, and Andreas Pitsillides. Energy conservation through social competitions in blocks of flats. In Proceedings of the First International Conference on Smart Grids and Green IT Systems (SMARTGREENS), Porto, Portugal, April 2012.

[26] OPOWER, 2015. http://opower.com/.

[27] Hunt Allcott. Social norms and energy conservation. Journal of Public Economics, 95(9-10):1082-1095, October 2011.

[28] Generaytor Inc. Generaytor, 2015. https://www.generaytor.com/.

[29] Gridmates Inc. Gridmates, 2015. http://www.gridmates.com/.

[30] Catherine Grevet, Jennifer Mankoff, and Scott D. Anderson. Design and evaluation of a social visualization aimed at encouraging sustainable behavior. In Proceedings of the 2010 43rd Hawaii International
Conference on System Sciences, HICSS '10, pages 1-8, Washington, DC, USA, 2010. IEEE Computer Society.

[31] Helen Ai He, Saul Greenberg, and Elaine M. Huang. One size does not fit all: applying the transtheoretical model to energy feedback technology design. In Proceedings of the SIGCHI Conference on Human Factors in Computing Systems, CHI '10, pages 927-936, New York, NY, USA, 2010. ACM.

[32] Jon Froehlich, Leah Findlater, and James Landay. The Design of Ecofeedback Technology. In Proceedings of the SIGCHI Conference on Human Factors in Computing Systems, CHI '10, pages 1999-2008, New York, NY, USA, 2010. ACM.

[33] B. J. Fogg. Persuasive technology: Using computers to change what we think and do. Ubiquity, 2002(5), December 2002.

[34] G. Michael Weiksner, B. J. Fogg, and Xingxin Liu. Six patterns for persuasion in online social networks. In Proceedings of the 3rd international conference on Persuasive Technology, PERSUASIVE '08, pages 151-163, Berlin, Heidelberg, 2008. Springer-Verlag.

[35] Electricity Authority of Cyprus, 2015. http://www.eac.com.cy/.

[36] Andreas Kamilaris, Marios Michael, Andreas Pitsillides, and Christos Fidas. A Case Study on the Use of Social Electricity by Cypriot Residents. Technical Report Technical Report No. TR-13-1, Department of Computer Science, University of Cyprus, September 2013. http://www.cs.ucy.ac.cy/docs/techreports/TR-13-1.pdf.

[37] Andreas Kamilaris, Andreas Pitsillides, and Christos Fidas. Social Electricity: A Case Study on Users Perceptions in Using Green ICT Social Applications. International Journal of Environment and Sustainable Development (IJESD), 2015. http://www.cs.ucy.ac.cy/akamil01/papers/Kamilaris_socialEl_study_cy.pdf (In Print).

[38] J. Kitzinger. Qualitative research: Introducing focus groups. British Medical Journal, 311:299-302, 1995.

[39] Singapore Power, 2015. www.singaporepower.com.sg/.

[40] Digital Agenda for Europe: A Europe 2020 Initiative. Collective Awareness Platforms, 2012. http://ec.europa.eu/digital-agenda/en/collectiveawareness-platforms.

[41] Current Cost, 2015. http://www.currentcost.com/.

[42] Social Electricity Online Platform (SEOP) European project, 2015. http://www.seop-project.eu.

[43] Sebastian Bamberg and Guido Möser. Twenty years after hines, hungerford, and tomera: A new meta-analysis of psycho-social determinants of pro-environmental behaviour. Journal of environmental psychology, 27(1):14-25, 2007.

[44] Judith IM De Groot and Linda Steg. Value orientations to explain beliefs related to environmental significant behavior: How to measure egoistic, altruistic, and biospheric value orientations. Environment and Behavior, 40(3):330-354, 2008.

[45] Christian A Klöckner and Anke Blöbaum. A comprehensive action determination model: Toward a broader understanding of ecological behaviour using the example of travel mode choice. Journal of Environmental Psychology, 30(4):574-586, 2010.

[46] Wokje Abrahamse, Linda Steg, Charles Vlek, and Talib Rothengatter. A review of intervention studies aimed at household energy conservation. Journal of environmental psychology, 25(3):273-291, 2005.

[47] Andreas Kamilaris and Andreas Pitsillides. Exploiting Demand Response in Web-based Energy-aware Smart Homes. In the First International Conference on Smart Grids, Green Communications and IT Energy-aware Technologies (Energy 2011), Venice, Italy, May 2011.

[48] Andreas Kamilaris, Yiannis Tofis, Chakib Bekara, Andreas Pitsillides, and Elias Kyriakides. Integrating Web-Enabled Energy-Aware Smart Homes to the Smart Grid. International Journal On Advances in Intelligent Systems, 5(1), July 2012.

[49] Gerald Gardner and Paul Stern. The Short List: The Most Effective Actions US Households Can Take to Curb Climate Change. Environment Science and Policy for Sustainable Development, 50(5), 2008.

[50] James O Prochaska and Carlo C DiClemente. Toward a comprehensive model of change. Springer, 1986. 